HISTORY OF MEDICINE

\title{
Malaria in the UK: past, present, and future
}

\section{T Chin, P D Welsby}

Postgrad Med J 2004;80:663-666. doi: 10.1136/pgmj.2004.021857

There is strong evidence that malaria was once indigenous to the UK, that global warming is occurring, and that human activity is contributing to global warming. Global warming will have a variety of effects, one of which will probably be the return of indigenous malaria.

M alaria in the UK is an imported disease but there is evidence that it was once indigenous. ${ }^{1}$ The use of land improvement techniques, antimalaria drugs, and improvements in standards of living at the end of the 19th century were responsible for its decline and eventual disappearance. It is postulated that global warming will allow malaria to establish itself in the UK.

\section{IS GLOBAL WARMING OCCURRING?}

The conventional wisdom answer is "Yes".

The global temperature is a result of interactions between the sea, the atmosphere, fluctuations in energy from the sun, volcanic eruptions, changes in the Earth's orbit, and quantities of greenhouse gases in the atmosphere which trap heat in much the same way that a greenhouse traps heat. The main greenhouse gases are water vapour (the biggest contributor), carbon dioxide, ozone, methane, nitrous oxide, and in recent years chlorofluorocarbons. ${ }^{1}$

Our planet has experienced numerous changes in climate. The last ice age, when there was widespread coverage of land by glaciers, ended 12000 years ago and for the last 10000 years the Earth's climate has been relatively warm. ${ }^{2}$

Reliable worldwide temperature records did not exist before the 1900s and indirect estimates for earlier eras have to be made using, for example, measurements of tree ring widths, ratios of oxygen isotopes in glacial ice, variations in species of microscopic animals trapped in sediments (different species thrive in different temperatures), and historical records of harbour closures from ice. The most frequently quoted estimates are those of Mann et $\mathrm{al}^{3}$ summarised in fig 1. The circumstantial evidence is that the Earth's temperature had been stable for the past 1000 years before 1900 when global warming, an increase in the average surface temperature of the Earth, occurred caused, so it is claimed, by increasing use of fossil fuels and a subsequent rise in atmospheric carbon dioxide.

The validity of this evidence has been questioned. The research was plagued by "collation errors, unjustifiable truncations of extrapolation of source data, obsolete data, geographical location errors, incorrect calculations of principle components and other quality control defects". ${ }^{4}$ Indeed the UK and the Earth may have experienced a medieval warming period (8001300) and the Little Ice Age (1300-1900), both occurring when human activity with greenhouse gas production would not have been relevant. ${ }^{5}$ It is possible that the global warming we have recently been experiencing is independent of human activities.

The Intergovernmental Panel on Climate Change agree that global warming is occurring and predict that the globe's average temperature will increase by $1-3.5^{\circ} \mathrm{C}$ by 2100 and that this would be associated with other environmental changes including a rise in sea level, increased global precipitation, and increased frequency of extreme weather events. ${ }^{6}$

\section{WHAT PART DOES HUMAN ACTIVITY PLAY IN GLOBAL WARMING?}

The main human postulated contribution to global warming is the burning of fossil fuels which release water vapour and approximately 6.5 billion tons of carbon into the atmosphere each year. Atmospheric concentrations of carbon dioxide have increased by almost $30 \%$ from preindustrial levels, although human activities represent only $3 \%$ of the carbon dioxide entering the atmosphere annually. The relationship between this slight increase in carbon dioxide and the increase in Earth's temperature over the past 100 years may not be causal.

Eighty percent of the carbon dioxide released from human activity occurred after 1940 during the industrial expansions of World War II and the post-war boom yet the observed warming began to take place before this (fig 2). Furthermore, between 1940 and 1980 there was slight global cooling despite an increase in fossil fuel burning. ${ }^{7}$ The United States disputed the causal association between carbon dioxide emission and global warming and refused to sign the 1992 Kyoto treaty designed to limit fossil fuel emissions.

No matter what the cause(s) global warming will continue in the short term. It would be interesting to see if life on Earth will adapt to minimise global warming-a kind of global homoeostasis as suggested in Lovelock's Gaia hypothesis ${ }^{8}$ with enhanced photosynthesis helping to slow the increase in atmospheric carbon dioxide. Increasing deforestation may well subvert this possibility.

\section{WILL GLOBAL WARMING AFFECT MALARIA?}

Malaria will be the disease most affected by global warming ${ }^{9}$ and an average global warming 


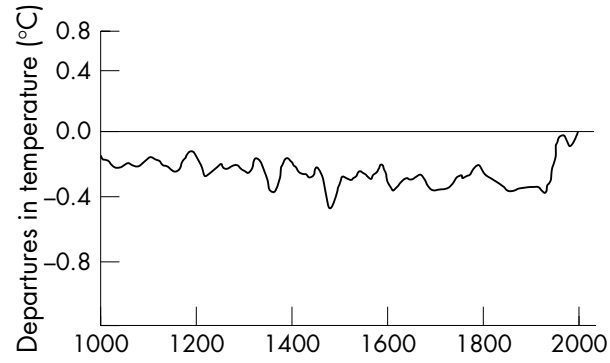

Figure 1 Departures in temperature over the past 1000 years in the northern hemisphere (from 1961-80 average).

of $3{ }^{\circ} \mathrm{C}$ by the year 2100 could increase the world annual incidence of malaria by $50-80$ million from the current $300-$ 500 million. $^{10}$ Temperature (and humidity) are among the most important factors for malaria transmission. Parasite multiplication inside the cold blooded mosquito reduces dramatically at temperatures between 20 and $27^{\circ} \mathrm{C}$ and parasite development ceases below $16^{\circ} \mathrm{C}$, so that malaria is confined by a $16^{\circ} \mathrm{C}$ minimum temperature line. ${ }^{11}$

Currently the range of the malarial parasites has not been significantly extended, but "airport malaria" occurs during hot weather in temperate countries, and small outbreaks of (vivax) malaria have occurred in Florida. ${ }^{12}$

It is predicted that UK temperatures will rise by $2-3.5^{\circ} \mathrm{C}$ by 2080, greater in the south and east than in the north and west, winters will become wetter, summers will become drier, summer precipitation may decrease by $50 \%$ or more by 2080 , and winter precipitation may increase by up to $30 \% .^{13}$

At least, global warming would increase the chance of acquisition of malaria by UK residents visiting malarial areas.

For mosquitoes warmer temperatures will ${ }^{14}$ :

- Increase populations.

- Increase lifespan.

- Produce a wider geographical distribution.

- Increase rates of parasite multiplication (which increases the likelihood of transmission to another host).

- Increase feeding on humans.

- Shorten the period between infection and infectivity.

- Increase duration of feeding patterns.

- Enlarge breeding sites and cause floods by increasing rainfall which will also disrupt antimosquito actions by humans.

- Increase the inoculation rate.

- Enhance breeding activity.

In the short term it is unlikely that vaccination, new antimalarial drugs, genetic engineering to produce malaria resistant mosquitoes, or encouragement of relevant mosquito predators will have significant impacts on malaria.

\section{MALARIA IN THE UK: THE PAST}

Circumstantial evidence is overwhelming that indigenous malaria ("the ague") occurred in the UK. Originally ague meant any acute fever. While epidemic fevers before the 14th century were labelled as agues or plague-agues, contemporary descriptions suggested that malaria was not the cause and may have been describing typhus. ${ }^{16} 17$

By the 14th century ague was usually referred to tertian or quartan fevers (fevers occurring every third or fourth day). Both established Plasmodium vivax, $P$ ovale and $P$ falciparum infections have a tertian periodicity, while $P$ malariae has a

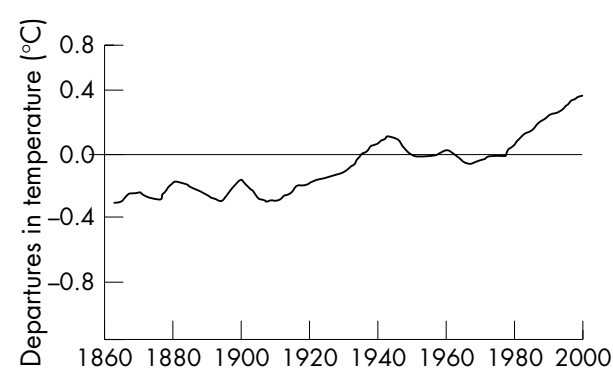

Figure 2 Departures in temperature globally over the past 140 years (from the 1961-90 average).

quartan periodicity. Geoffrey Chaucer in the Nonne Preeste's Tale of 1386 describes a tertian fever:

And if it do, I dare lay a grote,

That ye shul hav a fevere tertaine,

Or an aigu that may be yore bane.

Plasmodium vivax was the most likely cause of most UK malaria because the mortality was lower than that associated with $P$ falciparum infections in non-immunes, ague could relapse after recovery as can $P$ vivax, and patients with falciparum malaria either die or survive multiple attacks which eventually leave them immune.

References to quartan fevers in the 17th and 18th centuries suggest $P$ malariae also occurred here. Thomas Sydenham (1624-89), a leading 17th century English physician, wrote that anyone dwelling in the locality of marshes and lakes becomes "impressed with a certain miasma which produces a quartan ague". ${ }^{18}$ The topographer John Norden visited Essex in the 1590s but was unable to "commende the healthfulness of it, especiallie nere the sea coastes.... And other low places about the creeks which gave me a most cruell quarterne fever". ${ }^{\prime 9}$

There are many references to the association of ague with marshes, but only rarely to insects or mosquitoes. Sydenham (1624-89) in Observationes Medicae in 1667 included descriptions of paroxysms, both tertian and quartan, with references to insects "When insects do swarm extraordinarily and when...agues (especially quartans) appear as early as about midsummer, then autumn proves very sickly".

Shakespeare (1564-1616) made frequent reference to ague and recognised the connection between ague and marshy areas:

\author{
All the infections that the sun sucks up \\ From bogs, fens flats on Prosper fall and make him \\ By inch-meal a disease! \\ The Tempest II, 2, 1-3.
}

Five species of anopheline mosquitoes (the only species capable of transmitting human malaria) are indigenous to the UK, of which only Anopheles atroparvus breeds in sufficient numbers and in close enough association with humans to act as an efficient vector for malaria. ${ }^{20}$ The distribution of ague reflected the distribution of this species which prefers to breed in brackish water along river estuaries. For centuries ague was endemic in the Fens, the marshes of the Thames estuary and southeast Kent, low lying country in Somerset, and the Ribble district of Lancashire. The Lambeth and Westminster marshes in London were notorious. ${ }^{17}$ In the 18th and 19th centuries ague extended into Scotland, with occasional transmission as far north as Inverness. ${ }^{21}$ 
Epidemics of ague were associated with warmer ambient temperatures. Dobson noted a positive correlation between warm, dry summers between 1660 and 1810 and seasonal burial rates in Bradwell-juxta-Mare, a marsh parish in Essex $^{22}$ and Macdonald noted a strong relationship between high summer temperatures (above $16^{\circ} \mathrm{C}$ ) and mid-19th century ague in Kent. ${ }^{23}$ There was an unusually hot summer in 1661 in which, according to Pepys "the heat lasted on unbroken into the winter, which as to warmth and every other thing (is) just as it were the middle of May or June" and during this time the whole year "hath been very sickly". Sydenham in August of the same year describes epidemic "intermittent fevers" as "doing harmful mischief".

The strongest evidence that ague was malaria was successful treatment with chinchona (an extract containing quinine from the bark of a South American tree) which was introduced in the 16th century. It was effective in controlling ague but not for preventing relapses once the patient stopped taking it, ${ }^{24}$ a feature consistent with $P$ vivax infection.

Ague declined from 1800 onwards and began to vanish even where it did "very much reign at all times". ${ }^{25}$ Nuttall $e t$ al studied 18th and 19th century literary references and concluded there was widespread malaria initially with reduction in the incidence and distribution after the first quarter of the 19th century. ${ }^{26}$ This decline was underway well before the discovery of the parasitic life cycle by Laveran, Grassi, and Ross by the end of the 19th century. The causes of this decline are believed to be multifactorial ${ }^{17}{ }^{18}$ and include:

- Drainage of swamps may have reduced the density of $A$ atroparvus (which are still present today in marshy areas) to a low level.

- Better ventilated houses and living accommodation for humans and animals may have encouraged $A$ atroparvus to attack cows and horses (their preferred victims) rather than humans.

- Introduction of wider windows meant lighter rooms which would have discouraged the shade loving mosquitoes.

- Use of quinine in the 19th century would have reduced human reservoirs of infection.

- A fall in the price of chinchona enabling even the poor to buy.

Apart from a few cases when malaria was reimported, for example a local epidemic of vivax malaria after the return of soldiers during World War I on the Isle of Sheppey, the disease had disappeared from the UK by the beginning of the 20th century. ${ }^{18}$

\section{MALARIA IN THE UK: THE PRESENT}

Altogether 1.3 million UK residents visit malaria endemic areas each year. For the past decade between 1600 and 2500 cases with 9-15 deaths are reported annually. ${ }^{27}$ In descending numbers of patients these comprise UK travellers visiting friends and relatives, holidaymakers, business travellers, new entrants to the UK, and overseas visitors to the UK who fall ill during their visit. ${ }^{28}$

\section{MALARIA IN THE UK: THE FUTURE}

Inevitably, even in the absence of global warming, increasing numbers of returning travellers to the UK will have malarial parasites in their blood.

Global warming will extend the geographical range of malaria-transmitting mosquitoes. ${ }^{29}{ }^{30}$ Despite being regularly imported, malaria has failed to establish itself in the UK. For malaria to become indigenous there are four requirements. There must be:
(1) Returning travellers with primary infections.

(2) Appropriate mosquitoes to bite them.

(3) Summer temperatures to allow.

(4) Completion of intramosquito parasite stages such that malaria can be secondarily transmitted to bitten humans.

Also for these requirements to be met there must be:

(1) A failure of travellers to protect themselves against malaria.

(2) Suitable UK environments for mosquitoes.

(3) Secondary cases to be unrecognised and thus remain untreated.

(4) Secondary cases to be in turn bitten by UK mosquitoes in which

(5) Plasmodia become infectious to bitten humans (tertiary cases).

Initial outbreaks of indigenous malaria will probably be small and confined to a limited geographical area, most likely in marshy or coastal areas ( $A$ atroparvus, the most likely mosquito vector favours brackish water ${ }^{20}$ ) of south and east England.

\section{CONCLUSIONS}

Return of indigenous malaria in the UK has not yet occurred. The greater availability of cheap tropical and subtropical travel will result in more primary infections of humans with blood that could infect home grown mosquitoes. With increased global warming, occasional cases of secondary malaria will occur in UK residents who have not been abroad but the average tertiary spread will be to less than one other human and thus malaria will not establish itself (for malaria to persist, on average a patient with malaria would have to transmit infection to at least one other human, otherwise the infection would die out).

Within the next few decades tertiary spread of infection may occur in the UK, with spread to at least one other person. Indigenous malaria will then be with us.

\section{Authors' affiliations \\ T Chin, P D Welsby, Western General Hospital, Edinburgh, UK}

\section{REFERENCES}

1 Ledley TS, Sundquist ET, Schwartz SE, et al. Climate change and greenhouse gases. Eos. Transactions of the American Geophysical Union 1999;80:453.

2 Lamb HH. Climate history and the modern world. New York: Methuen, 1985.

3 Mann ME, Bradley RS, Hughes MK. Northern hemisphere temperatures during the past millennium: inferences, uncertainties and limitations. Geophysical Research Letters 1999;26:759-62.

4 Mclntyre S, McKitrick R. Corrections to the Mann et al (1998) proxy database and northern hemispheric average temperature series. Energy and Environment 2003;14:751-71.

5 Soon W, Baliunas S. Proxy climatic and environmental changes of the past 1000 years. Climate Research 2003;23:89-110.

6 Intergovernmental Panel on Climate Change. Climate change. Synthesis report, summary for policymakers. Watson RT, Core Writing Team, eds. Cambridge, UK: Cambridge University Press, 2001.

7 Hollander JM. Rushing to judgment. The Wilson Quarterly Spring, 2003:64.

8 Lovelock JE. Gaia. Oxford: Oxford University Press, 1979.

9 McMichael AJ, Ando M, Corcavallo P, ef al. Human population health. In: Watson RT, Zinowera Mc, Moss RH, eds. Climate change 1995-impacts, adaptations and mitigation of climate change. New York: Cambridge University Press, 1996.

10 Martens WJM, Rothman JJ, Niessen LW. Climate change and vector-borne diseases: a global modeling perspective. Global Environmental Change 1995;5: 195-209.

11 Roberts LS, Janovy J, eds. Foundations of parasitology. 6th Ed. London: McGraw-Hill, 2000.

12 Centre for Disease Control, Prevention (CDC). Local transmission of Plasmodium vivax malaria-Palm Beach County, Florida, 2003. MMWR Morb Mortal Wkly Rep 2003;52:908-11.

13 Department for Environment, Food and Rural Affairs. Climate change scenarios for the United Kingdom. London: DEFRA, 2002. 
14 Patz JA, Epstein BR, Burke TA, et al. Global climate change and emerging infectious diseases. JAMA 1996;275:217-23.

15 Fialho RF, Schall JJ. Thermal ecology of a malarial parasite and its insect vector: consequences for the parasites transmission success. Journal of Animal Ecology 1995;64:553-62.

16 Bruce-Chwatt $\mathrm{L}$, de Zulueta J. The rise and fall of malaria in Europe: a historico-epidemiological study. Oxford: Oxford University Press, 1979.

17 MacArthur W. A brief story of English malaria. British Medical Bulletin 1951;8:76-9.

18 Shute PG Maryon M. Malaria in England past, present and future. Royal Society of Health Journal 1974;94:23-9.

19 Norden J. Speculi Brittaniae pars: an historical and chorographical description of the county of Essex 1594. London, 1840.

20 Cranston P, Ramsdale C, Snow K, et al. Adults larvae and pupae of British mosquitoes (culicidae), A key scientific publication 48. Ambleside, Cumbria: Freshwater Biological Association, 1987.

21 Reiter P. From Shakespeare to Defoe: malaria in England in the Little lce Age Emerging Infectious Diseases 2000;6:1-11.

22 Dobson MJ. Marsh fever-the geography of malaria in England. Journal of Historical Geography 1980;6:357-89.
23 Macdonald A. On the relation of temperature to malaria in England. J R Army Med Corps 1920;35:99-119.

24 Dobson MJ. Malaria in England: a geographical and historical perspective. Parasitologia 1994:36:35-60.

25 James SP. The disappearance of malaria from England. Proceedings of the Royal Society of Medicine 1929;23:71-87.

26 Nuttall GHF, Cobbett L, Strangeways-Pigg T. The geographical distribution of Anopheles in relation to the former distribution of ague in England. Journal of Hygiene 1901;1:4-94.

27 Health Protection Agency. HPA Malaria Reference Laboratory. London: London School of Hygiene and Tropical Medicine (available at: www.malaria-reference.co.uk).

28 Bannister B. New guidelines on malaria prevention. Communicable Disease and Public Health 2001;4:82-3.

29 McMichael AJ, Ando M, Corcavallo $P$, et al. Human population health. In: Watson RT, Zinowera Mc, Moss RH, eds. Climate change 1995-impacts, adaptations and mitigation of climate change. New York: Cambridge University Press, 1996

30 Patz JA, Epstein BR, Burke TA, Balbus JM. Global climate change and emerging infectious diseases. JAMA 1996;275:217-23.

\section{FILLER}

\section{Obituary for an establishment figure}

$\mathrm{X}$ was a very fine fellow

Of views inevitably mellow.

He achieved dignity if not dignitas

And disowned views obviously crass.

Hardly missed a committee (of course)

Behind his back was judged "Stable and safe. A workhorse".

He always stood up to be counted, a man apart,

Often when others were standing, about to depart.

Symposia he supported, and colluded with colloquia,

Prominent at conferences far and indeed sometimes near.

Although he contributed to papers medical

Inevitably in references was always in et al.

Not a management monkey,

Rather management manqué.

Although overtly uninterested in pay,

The record shows he did it their way.

Hobbies and outside interests there were but a few,

For him it was "Not what you did, but who you knew".

He supported what he thought to be right, or what he was told was right.

His reward being a picture in obituary columns (alas black and white).

He leaves behind a wife who was bored,

Now revitalised-he was, predictably, well insured.

Now we regret that he has gone,

His reputation? "Second to one".

P D Welsby

Western General Hospital, Edinburgh EH4 2XU, UK; P.Welsby@ed.ac.uk 